\title{
La aportación de Lamano al Diccionario de la Academia $^{1}$
}

\author{
Montserrat Muriano Rodríguez \\ Universidade da Coruña
}

En 1925 la Real Academia Española publicó la decimoquinta edición de su Diccionario, pero no se trataba de una más, pues se introdujeron en ella algunos cambios de importancia. La Academia fue consciente de la singularidad de esta edición y lo puso de manifiesto en la Advertencia preliminar:

Esta edición décima quinta del Diccionario difiere de la décima cuarta probablemente más que cualquiera de las otras difiere de su inmediata anterior (DRAE-1925, p. VII).

El primero de estos cambios se percibe en el propio título, que pasa de ser Diccionario de la lengua castellana a Diccionario de la lengua española². El segundo fue la introducción de gran cantidad de regiona-

${ }^{1}$ El presente trabajo forma parte de un proyecto más amplio sobre el elemento salmantino en el Diccionario de la Academia.

2 En 1922 R. Menéndez Pidal postula ante la Academia la sustitución de la denominación lengua castellana por la de lengua española en las producciones de la Corporación. A pesar del voto desfavorable de al menos media docena de académicos, su propuesta salió adelante y, a partir de esa fecha, tanto la Gramática (1924) como el Diccionario (1925) pasaron a ser "de la lengua española" (vid. J. I. Pérez Pascual, 1998, pp. 158-159 y 174).

${ }^{3}$ En el punto 9 del prólogo de AUTORIDADES hay mención expresa a la introducción de voces dialectales en el diccionario, pero fueron muy pocas los que tuvieron cabida hasta la edición que nos ocupa:

En el cuerpo de esta obra, y en el lugar que les corresponde, se ponen várias voces peculiares y próprias, que se usan freqüentemente en algunas províncias y réinos de España, como en Aragón, Andalucía, Astúrias, Murcia, \&c. aunque no son comúnes en Castilla: y en las de Aragón se omiten las que vienen de la Léngua Lemosina, y no están autorizadas con los Fueros, Leyes, y Ordenanzas de aquel réino.

Sobre la inclusión de regionalismos en AUTORIDADES vid. A. Salvador Rosa (1985). 
lismos y americanismos, dado que, hasta el momento, estaban prácticamente ausentes de la nomenclatura del Diccionario $^{3}$. El cambio en el título se ampara precisamente en "esta mayor atención consagrada a las múltiples regiones lingüísticas, aragonesa, leonesa e hispanoamericana" (DRAE-1925, p. VIII), y a glosar esta novedad dedica gran parte de la Advertencia:

Ha concedido también atención muy especial a los regionalismos de España y de América que se usan entre la gente culta de cada país, voces que estaban escasamente representadas en las ediciones anteriores. El provincialismo de España encierra una riqueza léxica de inapreciable valor, porque conserva viva gran porción de vocablos pertenecientes al antiguo fondo patrimonial de nuestro idioma (DRAE-1925, p. VII).

Nuestro artículo pretende examinar tan solo el papel que desempeñó en la introducción de artículos con acepciones con la marca diatópica "Sal." el vocabulario de José Lamano y Beneite4.

El repertorio léxico del canónigo salmantino se inscribe en el ámbito de los estudios de Lingüística histórica y de Dialectología iniciados por Ramón Menéndez Pidal a principios de este siglo. Consta de 5.237 entradas y 6.427 acepciones del ámbito de la agricultura, la ganadería, la flora y fauna, cultura popular, juegos, etc. de la provincia de Salamanca. En su recogida de datos actuaron como informantes especialmente los párrocos rurales, pero también veterinarios, maestros, médicos y farmaceúticos. Obtuvo así una información tan precisa que, en bastantes ocasiones, da cuenta de la zona o localidad donde es utilizado ese término (Ribera del Duero, Alba de Tormes, Cantalapiedra, Sierra de Béjar, Tierra de Alba...).

Por otra parte, son autoridades léxicas gran cantidad de escritores representativos del habla de Salamanca, desde Juan del Encina o Bartolomé Torres Naharro a los contemporáneos José $\mathrm{M}^{\mathrm{a}}$ Gabriel y Galán o Miguel de Unamuno. Y también demuestra conocer bien los trabajos de El Brocense, Nebrija, Valdés, Alonso Garrote, etc.

Pero hay algunas obras clásicas en las que centró toda su atención: el Tesoro de la lengua castellana (1611) de Sebastián de Covarrubias y

4 Para recabar más información sobre el método de trabajo de J. Lamano y Beneite (1872-1918) vid. el excelente Prólogo de A. Llorente Maldonado a la edición facsímil de El dialecto vulgar salmantino, al que, a partir de ahora, me referiré como Lamano. 
el Vocabulario de refranes (1625) de Gonzalo Correas. No olvida tampoco varios glosarios de autores de su tiempo: el Vocabulario anejo a la Vida de Don Quijote y Sancho (1905) de Miguel de Unamuno, el Vocabulario charruno (1903) de Manuel Fernández de Gata y Galache y el Vocabulario incluido por Luis Maldonado en su colección de cuentos Del campo y de la ciudad (1903).

Por otra parte, la vinculación de este trabajo con la Academia se manifiesta desde un primer momento, pues fue premiado y publicado por la Corporación en $1915^{5}$.

Pero no ha sido únicamente este hecho el que nos ha llevado a relacionar el LAMANO con la edición de 1925, sino las propias definiciones del diccionario localizadas geográficamente en Salamanca ${ }^{6}$. En algunas de ellas podemos comprobar claramente que el punto de referencia fue este vocabulario, pues se repiten tal cual, en otras se introducen ligeros cambios -suscitados muchas veces por el excesivo enciclopedismo del LAMANO-; no obstante, en algunas ocasiones pudo haber sido algún aca-

5 Este hecho está reflejado en la portada: EL DIALECTO VULGAR SALMANTINO | POR | JOSÉ DE LAMANO Y BENEITE | OBRA LAUREADA CON ACCESIT EN PÚBLICO CERTAMEN| POR


Tipografia Popular (IMP. de "El Salmantino") | Plazuela de San Isidro | 1915.

6 En este sentido son especialmente esclarecedoras las palabras de A. Llorente Maldonado en el Prólogo al LAMANo:

Es, este Vocabulario, el repertorio léxico más completo de todos los vocabularios provinciales, y uno de los repertorios más nutridos de todos los que han aparecido en el ámbito de los léxicos dialectales, regionales, provinciales y locales del dominio lingüístico español. Y, además, ha tenido el alto honor de que gran parte de las voces que en el aparecen hayan pasado al Diccionario de la Real Academia, al DRAE, donde muchas de ellas figuran con la indicación Sal. (voz usada en Salamanca) (LAMANO, pp. V-VI).

En la misma dirección van las palabras de L. Cortés y Vázquez en su valoración del vocabulario del clérigo salmantino:

Una de las consecuencias de su aparición fué el que no pocas docenas de palabras salmantinas pasaran a engrosar el caudal del Diccionario académico (1957a, p. 137).

7 Hasta el año de publicación de la $15^{\mathrm{a}}$ edición del DrAE únicamente se puede hablar del vocabulario del farmacéutico de Salamanca M. Fernández de Gata y Galache (1903) como introductor de voces propias de la provincia. En la actualidad contamos con gran cantidad de aportaciones al estudio del elemento salmantino; especialmente relevantes son los trabajos del académico correspondiente A. Llorente Maldonado y los de L. Cortés y Vázquez. 
démico de la época u otra obra dialectal los causantes de la inclusión en el Diccionario de estas entradas con sus nuevas acepciones ${ }^{7}$.

En el ámbito del léxico provincial recogido en la última edición del DRAE se localizan 636 acepciones en Salamanca, 574 con marca 'Sal.' y 62 con marca Salamanca, algunas de ellas compartidas con otras localizaciones geográficas (Zamora, León, Aragón, algún país de Hispanoamérica, etc.). Se convierte así en la provincia donde se localizan más acepciones en el Diccionario académico, seguida a gran distancia por Álava (285), León (236), Burgos (89) y Zamora (68); es evidente, pues, que el elemento salmantino ocupa un lugar destacado en el Diccionario académico.

Pero fue a partir de la edición decimoquinta cuando se ha iniciado este interés con la introducción de nada menos que 606 acepciones localizadas en esta provincia -598 con marca 'Sal.' y 8 con marca Salamancao compartidas con otros lugares, bien sea León, Zamora, Asturias o alguna nación americana. La mayoría de ellas hacen referencia a las actividades agrícolas y ganaderas y al ámbito rural en general (el folklore, la alimentación, la vestimenta, la fiesta...).

Procuraré examinar alguna de ellas, con la intención de mostrar varios aspectos especialmente relevantes:

1) Correspondencia entre la definición de LAMANO y la del DRAE- 1925.

2) Ligeros cambios en la definición del DRAE-1925 con respecto a la de LAMANO: alteración en el orden de las palabras, cambio en algún término de la definición, retoques de estilo...

3) Definiciones de LAMANo que tienen carácter enciclopédico o son demasiado explicativas y que el DRAE-1925 simplifica.

4) El reflejo de LAMANO en la última edición académica.

Sin lugar a dudas, la consulta del denominado Fichero de cambios de la Real Academia, en el que se encuentran las papeletas con adiciones y enmiendas de una edición del diccionario a otra ha resultado especialmente provechosa a la hora de demostrar la filiación entre el LAMANO y el Diccionario académico ${ }^{8}$. Al abordar este trabajo, mi consulta se ha cen-

8 Agradezco a la Real Academia Española el haberme permitido utilizar dicho Fichero, en especial a $\mathrm{M}^{\mathrm{a}}$ Dolores Seijas Cotarelo quien me ayudó a desempolvar gran cantidad de papeletas. Algunas de éstas contienen información valiosísima sobre la fecha exacta en que se aprobó la adición o enmienda, la persona que la introdujo -ya sea académico o colaborador- e incluso los cambios que sufrió la definición hasta su inclusión en la edición del Diccionario. 
trado en las adiciones y cambios surgidos entre la decimocuarta (1914) y la decimoquinta edición (1925):

1) En bastantes ocasiones la definición de DRAE-1925 coincide con la de LAMANO:

acabación 'acabamiento, abatimiento, postración'.

adrar 'repartir las aguas para el riego'.

bornear 'hacer mudanzas y figuras con los pies en el baile'9. cancillera 'cuneta o canal de desagüe en las lindes de las tierras labrantías'.

cañiza 'conjunto de cañizos unidos entre sí por medio de pielgas, que sirve para formar corraliza o redil en que se encierran las ovejas en el campo'.

escabuchar 'pisar los erizos de las castañas para que suelten el fruto'.

jijeo 'grito con que los mozos suelen terminar los cantares y tonadas, especialmente en las rondas' 10 . rengar 'descaderar, derrengar'. rutil 'hato pequeño de ganado cabrío o lanar'.

2) Otras definiciones sufren ligeros cambios con respecto a la de LAMANO.

2.1) En algunas ocasiones simplemente hay diferente orden de las palabras:

bastonear 'comer bastones el ganado' (DRAE-1925) /

'comer el ganado bastones' (LAMANO).

cernear 'mover con violencia alguna cosa' (DRAE-1925) /

'mover alguna cosa con violencia' (LAMANO).

escorrozo 'melindre, remilgo' (DRAE-1925) / 'remilgo, melindre' (LAMANO).

9 Hay papeleta del Fichero con esta adición en la que figura la definición y debajo de ella la referencia 'Lamano. V. Borneo en el Dic.'.

10 En el Fichero se reproduce esta definición con la siguiente cita: 'Lam. con 2 autor. de Maldonado'; se trata de dos citas de la obra de L. Maldonado Del campo y de la ciudad. Jijeo se define en DRAE-1992 como 'acción y efecto de jijear', sin localización geográfica; en cambio, sí encontramos localizada en Salamanca la voz jijear 'lanzar el grito jubiloso, $\mathrm{i} i \mathrm{i}, \mathrm{ji}$, $j i$ !'. 


\section{2) También se puede cambiar alguna palabra:}

acogotar 'herirse el buey en el cogote' (DrAE-1925) / 'herirse el buey en la cogotera' (LAMANO) ${ }^{11}$. ahijadero 'prado o majadal que se reserva para que ahijen las ovejas en la temporada del parto y cría de los corderos' (DRAE-1925) / 'prado o majadal que se reserva para ahijar las ovejas en la temporada de la parición y cría del corderaje' (LAMANO) ) ${ }^{12}$.

sacadera 'oveja que se da de excusa al pastor y que puede escoger y sacar de entre todas las del rebaño' (DRAE-1925) / 'la oveja que dan de escusa al pastor y que puede escogerla o sacarla de entre todas las del rebaño' (LAMANO) ${ }^{13}$.

${ }^{11}$ En DRAE-1925 cogote y cogotera no son equivalentes. El primer término figura allí como 'parte superior y posterior del cuello', acepción que corresponde a la empleada en la definición de acogotar en el Diccionario académico. No sucede lo mismo con cogotera, que hace referencia al 'pelo rizado y compuesto que cae sobre el cogote' por tanto, la modificación del Diccionario académico es coherente con su información léxica.

12 Corderaje no figura como entrada en DRAE-1925, pero sí en la última edición del Diccionario académico (p. 571): 'm. Chile. borregada'.

${ }^{13}$ Escusa no figura como entrada en DRAE-1925, sólo he encontrado escuso (a) ' $\mathrm{m}$. adv. ant. A excuso'. Sin embargo, en DrAE-1992 encontramos trasladadas a escusa algunas de las acepciones que en DRAE-1925 corrrespondían a excusa y otras nuevas:

excusa. f. Acción y efecto de excusar o excusarse. $\| 2$. Motivo o pretexto que se invoca o se utiliza para eludir una obligación o disculpar alguna omisión. || 3. V. Paños de excusa. $\| 4$. Cualquiera de los provechos y ventajas que por especial condición y pacto disfrutan algunas personas según los estilos de los lugares. || 5. For. Excepción o descargo. || 6. Excusabaraja. Una EXCUSA de fresas. \| A excusa, o a excusas. m. adv. ant. Con disimulo o cautela (DRAE-1925).

escusa. (Del lat. absconsus, escondido.) f. escusabaraja. $\| 2$. Cualquiera de los provechos y ventajas que por especial condición y pacto disfrutan algunas personas según los estilos de los lugares. || 3 . Derecho que el dueño de una finca o de una ganadería concede a sus guardas, pastores, etc., para que puedan apacentar, sin pagar renta, un corto número de cabezas de ganado de su propiedad, y esto como parte de la retribución convenida. $\| 4$. Conjunto de las cabezas de ganado a que se aplica este derecho. || 5. Entre ganaderos, res o cabeza de ganado horra. $\| 6$. V. paños de escusa, o escusas. loc. adv. Con disimulo o cautela (DRAE-1992).

En esta última edición del DRAE ya se corrige 'excusa' por 'escusa' en la definición de sacadera y se emplea dicho término en su tercera acepción. También figuran como artículos separados excusa 'f. Acción y efecto de excusar o excusarse. $\| 2$. Motivo o pretexto que se invoca o se utiliza para eludir una obligación o disculpar alguna omisión. || 3. Der. Excepción o descargo' y excusa ${ }^{2}$ que remite a escusa. 
2.3) Son muchos los ejemplos en los que se pasa de una definición bastante explicativa por parte de LAMANO a la remisión a otra entrada en el Diccionario ${ }^{14}$ :

sonique 'follador' (DRAE-1925) / 'el chico que en la fragua tiene por oficio tirar del cordel o de la cadena del fuelle' (LAMANO).

cañizo 'cancilla' (DrAE-1925) / 'especie de tablado o angarrilla, formada por dos palos perpendiculares y tres horizontales, que se emplea para cerrar, a modo de portillo, la entrada de cortinos y corrales' 15 .

tajadero 'tajadera, 2. ${ }^{\text {a }}$ acep.' (DRAE-1925) / 'el rollo de madera, plana en la superficie, que sale en medio de una fuente o plato, también de madera, y en el cual se coloca la carne que se ha de cortar' (LAMANO).

3) Especialmente significativo es el tratamiento de las definiciones enciclopédicas que hace LAMANO; ello no puede ser criticado desde un punto de vista estrictamente lexicográfico, pues este vocabulario no fue concebido teniendo en cuenta los principios de la definición lexicográfica que hoy en día están perfectamente clarificados.

${ }^{14}$ Ese criterio de remisión a otra entrada lleva al Diccionario académico, en muchos casos, a definiciones circulares. En este sentido tiene especial interés el Preámbulo a DRAE-1970, edición en la que se suprimen gran parte de estas referencias a otras entradas del Diccionario u a otras acepciones:

Por un acuerdo de la Academia, las referencias numéricas a otras acepciones se han suprimido, dando al lector la sola definición directa, entera o reducida de la acepción. Aparte de este cambio acordado, se han aplicado las definiciones directas a un gran número de voces definidas antes por referencia a un sinónimo, que muchas veces no era completamente equivalente, que con frecuencia era oscuro para el lector y cuyo sentido sólo se descubría a veces en un segundo o tercer expediente. La absoluta supresión de las definiciones indirectas, que hasta hoy es sólo ideal de un diccionario, no se ha logrado del todo en éste, por razones internas y editoriales, pero se ha avanzado mucho en el propósito (p. VII).

15 Es muy interesante la papeleta de cañizo en el Fichero de cambios en la que no sólo aparece tachada una primera opción, más explicativa ('especie de puerta formada por dos palos verticales y tres horizontales que se emplea para cerrar'), sino que se añade otra nueva por encima de ésta: 'Cancilla'. La definición de LAMANo (pp. 321322) también se desecha, quizá por ser demasiado explicativa; igual que en alguna otra ocasión, se ha tachado 'Lam.' en la papeleta. 
Ejemplos de esta definición enciclopédica son:

alzapón 'tapa de paño, como de una cuarta en cuadro, que va desde la ingle a dar de cadera a cadera, dejando a los lados sendas aberturas, a modo de bolsillos. Sujétase en el extremo superior o por una correa que ciñe todo el cuerpo, o por medio de botones' (LAMANO) / 'portezuela que tapa la parte anterior de los antiguos pantalones' (DRAE-1925).

bayón 'planta que se cría en las riberas, alta como la espadaña, tallo redondo y sin hojas, al remate echa unas bolas blancas cubiertas de pelusa. El tallo se aplica para hacer esterillas que emplean a guisa de colchoncillos en los escaños, y en los estrados sobre los cuales colocan el pan antes y después de cocerlo' ( LAMANO) / 'espadaña, I. acep.' (DrAE-1925) ${ }^{16}$.

candorga 'planta parietal, de hojas largas y carnosas. La emplean contra las hechicerías de las malas, que así llaman, en la Ribera (donde tiene este vocablo uso), a las brujas. La mujer, que se cree perseguida de las malas, introduce la planta dentro de la camisa, junto a la cintura, cerca del vientre o andorga, de donde tal vez traiga origen este vocablo' (LAMANO) / ' planta parietal de hojas largas y carnosas, que el vulgo femenino emplea como supersticioso amuleto contra brujerías, llevándola en contacto con la piel cerca de la cintura' (DrAE-1925).

canga 'arado dispuesto para una sola caballería. Se compone de una vara, en forma de horquilla larga, en donde entra la caballería; del centro exterior de la horquilla sale la vara, que se ajusta al timón' (LAMANO)/ 'arado dispuesto para una sola caballería' (DrAE-1925).

4) Para finalizar, no es posible obviar el cotejo de LAMANo / DRAE1925 y la última edición del Diccionario académico.

Es interesante hacer notar que no todas las entradas de DRAE-1925 figuran en LAMANO ${ }^{17}$. Es el caso de ahorrar, aturrar, montaraz, montaraza, farinato $^{18}$, tabina, torna, vegada, etc.

Por otro lado, 13 artículos de DrAE-1925 y de LAMANO con acepcio-

16 Sobre la remisión a otras entradas en el Diccionario de la Academia vid. nota 14.

${ }^{17}$ No se recogen en LAMANo 32 entradas del Diccionario académico; un análisis pormenorizado de éstas forma parte del proyecto de investigación del que el presente trabajo es un anticipo.

18 A pesar de no figurar como entrada en LAMANO, el Fichero de la Academia hace referencia a él en la papeleta de este término con la siguiente observación: 
nes con marca diatópica 'Sal.' han desaparecido de la macroestructura de la última edición del Diccionario académico: acabación, acarbarse, adivinalla, apegostrar, candín, candongueo, chaguarzo, empergar, empergue, gadejón, lover, mudancia y tiricia. Otros como agorería, aguachinar, andancio, andulencia, berreón, desosegar, empollar, etc., conservan la acepción, pero sin mención de localización geográfica alguna.

En mi análisis de los testimonios estudiados he encontrado algún elemento más de contraste, como la variación en algunas entradas. En algún caso se trata de variantes meramente gráficas, sin mayor trascendencia, así carcavonera 'peñascal' (DRAE-1925, DRAE-1992) / carcabonera (LAMANO) ${ }^{19}$. En otras la Academia ha optado por no recoger toda la riqueza de las variantes dialectales: donosilla 'comadreja' (DRAE-1925, DRAE1992), dolonsilla, donecilla y donocilla (LAMANO) ${ }^{20}$. Por último, en algunos casos el Diccionario académico parece no haber reproducido con exactitud la información de LAMANO, pues en la segunda acepción de atuendo 'Sal. mueble viejo e inútil' (DRAE-1925, DRAE-1992) recoge la información que el cura salmantino ofrece sobre la forma dialectal atruendo 'cosa desusada, antigualla, mueble viejo e inútil' (LAMANO) ${ }^{21}$.

Creo que a la vista de los datos aportados, cabe concluir que $E l$ dialecto vulgar salmantino fue una obra de referencia muy importante, a la hora de incluir en la edición decimoquinta del Diccionario, léxico propio de la provincia de Salamanca.

p. a. Salamanca. Embutido de pan amasado de manteca de cerdo, sal y pimienta. No trae Farinato Lamano; pero en la voz "frijuela" dice: bodrio con $\mathrm{q}^{\mathrm{e}}$ se condimenta y adoba el farinato. También en "farelo" dice: farinato.

Se comprueba así que el vocabulario del canónigo fue en todo momento obra de referencia a la hora de introducir las acepciones de Salamanca en el DrAE. La versión definitiva de la definición de este término en DRAE-1925 es 'Embutido de pan amasado con manteca de cerdo, sal y pimienta'

19 Sobre la forma carcabonera, vid. J. Corominas y J. A. Pascual (1980-1991, s. v. cárcavo).

20 En este caso la Academia ha optado por la forma donosilla que no recoge LAMANO, pero sí M. Fernández de Gata y Galache (1903, p. 81). C. Sánchez León (1995, p. 95) incluye en su vocabulario únicamente la forma doncelleta que también encontramos en A. Llorente Maldonado (1947, pp. 190-191 y 234). V. García de Diego (1985, s. v. dominicellus) recoge las variantes donocella (también como propia de León), dolonsilla y donecilla.

21 M. Fernández de Gata y Galache (1903, p. 74) ya incluye la forma atruendo con esta acepción. Sobre esta variante vid. también J. Corominas y J. A. Pascual (1980-1991, s. v. atuendo), M. L. Wagner (1931, p. 238) y L. Spitzer (1943, p. 1). 


\section{BIBLIOGRAFÍA}

\section{REPERTORIOS LEXICOGRÁFICOS}

Autoridades: ReAl Academia Española (1726-1739): Diccionario de la lengua castellana, Madrid, Imprenta Real; facsímil, en Madrid, Gredos, 1963.

Corominas, Joan y José Antonio Pascual (1980-1991): Diccionario crítico etimológico castellano e hispánico, Madrid, Gredos.

DRAE-1925: Diccionario de la lengua española, Madrid, Talleres Tipográficos de Calpe, $15^{\mathrm{a}}$ ed.

DraE-1970: Diccionario de la lengua española, Madrid, Espasa-Calpe, $19^{\mathrm{a}}$ ed.

DRAE-1992: Diccionario de la lengua española, Madrid, Espasa-Calpe, $21^{\text {a }}$ ed.

FERNÁNDEZ DE GATA Y GALACHE, Manuel (1903): "Vocabulario charruno", en Ociosidades, Salamanca, Imp. y Lib. de Francisco Núñez, pp. 69-104.

LAMANO Y BENEITE, José (1915): El dialecto vulgar salmantino, Salamanca, Tipografía Popular (Imp. de "El Salmantino"); facsímil en Salamanca, Ediciones de la Diputación de Salamanca, 1989.

GARCÍA DE DIEGO, Vicente (1985): Diccionario etimológico español e hispánico, Madrid, Espasa Calpe, $2^{\mathrm{a}}$ ed.

\section{EsTUDIOS}

AGERO TEIXIDOR, Rufino (1966): Palabras y frases bejaranas, Gráficas Tapia, Béjar.

Alvar EzQuerra, Manuel (1993a): "El Diccionario de la Academia en sus prólogos", en Lexicografia descriptiva, Barcelona, Biblograf, pp. 215-239.

ALVAR EZQUERRA, Manuel (1993b): "Los regionalismos en los diccionarios y vocabularios regionales", en Lexicografia descriptiva, Barcelona, Biblograf, pp. 313-331.

CORTÉS Y VÁZQUEZ, Luis (1951): "Ganadería y pastoreo en Berrocal de Huebra (Salamanca)", Revista de Dialectología y Tradiciones populares, VIII, pp. 425-467 y 563-595. 
CORTÉS Y VÁZqueZ, Luis (1957a): "Contribución al vocabulario salmantino", Revista de Dialectología y Tradiciones populares, XIII, pp. 136-189.

CORTÉS Y VÁZQUEZ, Luis (1957b): Las ovejas y la lana en Lumbrales, Imprenta Núñez, Salamanca.

GARCíA-MACHO, $\mathrm{M}^{\mathrm{a}}$ Lourdes (1989): El léxico de Luis Maldonado, Madrid, UNED.

Iglesias Ovejero, Ángel (1982): El habla de El Rebollar, Salamanca, Universidad de Salamanca.

Llorente MALdonAdo DE Guevara, Antonio (1947): Estudio sobre el habla de la Ribera (comarca salmantina ribereña del Duero), Salamanca, Consejo Superior de Investigaciones Científicas.

Llorente MALdonado DE Guevara, Antonio (1958-1959): "Importancia para la historia del español de la aspiración y otros rasgos del salmantino noroccidental", Revista de Filología Española, XLII, pp. 151-165.

Llorente Maldonado de Guevara, Antonio (1962): "Don Luis Maldonado y su salmantinismo lingüístico", en Homenaje a Don Luis Maldonado 1860/1960, Salamanca, Centro de Estudios Salmantinos, pp. 43-53.

Llorente Maldonado DE Guevara, Antonio (1981-1989): "Las denominaciones del 'camino de ganado' en las provincias de Zamora, Salamanca y Ávila", en Homenaje al profesor Luis Rubio García, Estudios Románicos, Facultad de Filosofía y Letras, Universidad de Murcia, V, pp. 707-805.

Llorente MaldonAdo DE Guevara, Antonio (1982): "El habla de Salamanca y su provincia", Boletín de la Asociación Europea de Profesores de Español, XIV, 26, pp. 91-100.

Llorente MaldonAdo DE GueVARA, Antonio (1983): "Correspondencia entre el léxico salmantino y el léxico de Aragón, Navarra y Rioja”, en Serta Philologica Fernando Lázaro Carreter, Madrid, Cátedra, I, pp. 329-341.

Llorente Maldonado de Guevara, Antonio (1985): "En la Salamanca de las sonoras arcaicas (Las andanzas de un aprendiz de dialectólogo)", en Homenaje a Alvaro Galmés de Fuentes, Madrid, Gredos, I, pp. 233-243.

LLORENTE MALDONADO DE GUEVARA, Antonio (1986b): "Las hablas vivas de Zamora y Salamanca en la actualidad", en Lenguas peninsulares y proyección hispánica, Madrid, Instituto de Cooperación 
Iberoamericana, pp.107-131.

LLORENTE MALDONADO DE GUEVARA, Antonio (1986c): Aspectos lingüísticos de La Tierra de Béjar, Béjar, Instituto de Bachillerato Ramón Olleros Gregorio.

Llorente Maldonado DE Guevara, Antonio (1991): "Las denominaciones del erial en las provincias de Zamora, Salamanca y Ávila", en Homenaje a Luis Cortés Vázquez, Salamanca, Ediciones Universidad, pp. 539-552.

LORENZO, Emilio (1949): "Notas al vocabulario de Lamano", Revista de Dialectología y Tradiciones Populares, V, pp. 97-109.

MaldonAdo, Luis (1925): "El dialecto charruno", en Homenaje a D. Ramón Menéndez Pidal, Madrid, Librería y casa editorial Hernando, I, pp. 155-160.

Marcos CASQUero, Manuel Antonio (1979): El habla de Béjar: Léxico,

Salamanca, Gráficas Europa.

Pérez Pascual, José Ignacio (1998): Ramón Menéndez Pidal, Valladolid, Junta de Castilla y León.

REAL ACADEMIA EsPaÑola (1928): Catálogo de las obras publicadas por la Real Academia Española, Madrid, Tipografía de la Revista de Archivos.

SALVADOR Rosa, Aurora (1985): "Las localizaciones geográficas en el Diccionario de Autoridades", Lingüística Española Actual, VII, pp. 103-139.

SÁNCHEZ León, Cándido (1995): Palabras y expresiones usadas en la provincia de Salamanca, rev., reelab., ed. e introd. Antonio Llorente Maldonado de Guevara, Salamanca, Caja de Salamanca y Soria.

SÁnchez SEvilla, Pedro (1928): "El habla de Cespedosa de Tormes (en el límite de Salamanca y Ávila)", Revista de Filología Española, XV, pp. 131-172 y 244-282.

SPITZER, Leo (1943): “Estudios etimológicos", Anales del Instituto de Lingüística, III, pp. 1-23.

WAGNER, Max Leopold (1931): "Zum Judenspanischen von Marokko", Volkstum und Kultur der Romanen, IV, pp. 221-245. 